\title{
Construction of a Learning Satisfaction Scale for Nursing Students with High-Fidelity Simulation Based on the Delphi Method
}

\author{
Jing Geng*, Jiahui Zhang, Liping Li, Ziying Zhang \\ Department of Nursing, Medical School of Yangtze University, Jingzhou, China \\ Email: *gengjing89@163.com
}

How to cite this paper: Geng, J., Zhang, J. H., Li, L. P., \& Zhang, Z. Y. (2020). Construction of a Learning Satisfaction Scale for Nursing Students with High-Fidelity Simulation Based on the Delphi Method. Open Journal of Social Sciences, 8, 1-10. https://doi.org/10.4236/jss.2020.85001

Received: August 11, 2019

Accepted: May 5, 2020

Published: May 8, 2020

Copyright $\odot 2020$ by author(s) and Scientific Research Publishing Inc. This work is licensed under the Creative Commons Attribution International License (CC BY 4.0).

http://creativecommons.org/licenses/by/4.0/ (c) (i) Open Access

\begin{abstract}
Objective: To develop a learning satisfaction scale for Chinese nursing students with high-fidelity simulation. Methods: We collected scale items through literature screening and expert consultation questionnaire. Delphi method was implemented. Using two rounds of Delphi method, 18 professional experts offered the results. Results: The response rate in each of both rounds was above $80 \%$. The authority coefficient of experts was 0.87 in round 1 and 0.88 in round 2. The coefficient of variation in each round was below $30 \%$. The Kendall's coefficient of concordance W was 0.809 in round 1 and 0.848 in round 2 ( $P<0.05$ for both). Cronbach's alpha was 0.77 . The 20 -item scale included four dimensions being named as simulation authenticity, teaching methods, teaching content and teaching effect. Conclusion: the learning satisfaction scale for nursing students with high-fidelity simulation based on the Delphi method is reliable for assessing learning satisfaction of Chinese nursing students with high-fidelity simulation.
\end{abstract}

\section{Keywords}

Delphi Method, Nursing Students, High-Fidelity Simulation, Learning Satisfaction, Scale

\section{Introduction}

Patient expectation level improves followed by the improvement of modern medicine, and the operational practices of nursing students during clinical internships are reduced, then clinical practice effects are affected (Parr \& Sweeney, 2006; Ziv, Small, \& Wo, 2000). Facing the challenge of traditional nursing education, nursing educators continue to explore new teaching methods such as 
situation simulation and high-fidelity simulation teaching (Baptista, Martins, Pereira, \& Mazzo, 2014). High-fidelity simulation teaching provides students with a near-real clinical environment, which not only enhances the development of students' operational skills, but also enhances the ability of evaluation, team cooperation, emergency treatment and self-regulated learning (Leigh, 2008; Wu, Liu, \& Wu, 2014; Xiao \& Wu, 2009). In 1988, the human patient simulator is first applied in the United States (Gaba \& DeAnda, 1988). In 2004, physiology-driven high-fidelity simulators were first introduced to carry out emergency medical education domain by the Xuanwu hospital of Capital Medical University (Sun et al., 2011). With the reform of the teaching methods of domestic nursing education, the application of high-fidelity simulation teaching is increased. Meanwhile, the transformation has brought many opportunities and challenges for nursing teachers and students. The effect of high-fidelity simulation teaching has been paid more attention. The evaluation of students' learning satisfaction could reflect the study effect in some degree. However, a learning satisfaction scale for nursing students with high-fidelity simulation has not been developed in domestic at the present. In the study, from April 2018 to July 2018, the Delphi expert consultation was used to construct the scale which provides a tool for evaluating learning effect of nursing students with the high-fidelity simulation.

\section{Methods}

\subsection{Research Team}

Our Research Team included 1 professor, 1 supervisor nurse, 1 lecturer and 1 postgraduate student. All members' research direction is the nursing education and all have had the experience of high-fidelity simulation exercises. The main work was to form the sketch of index system, select experts, conduct the Delphi method, and test the credibility of the study with reliability, positive coefficient, authoritative coefficient and Kendall coefficient.

\subsection{Establishment of the Draft of Indexes}

\subsubsection{Literature Review}

A comprehensive search of literature databases was conducted by two researchers. A combination of $\mathrm{MeSH}$ and free-text terms was applied to implement search strategies. MeSH and free-text terms for queries included "high-fidelity simulation", "fidelity", "simulation", "student satisfaction", "human patient simulation manikin”, “computer simulation”, "program evaluation", and "learning satisfaction”. Foreign studies that reported includes Jefferies' simulation nursing teaching satisfaction scale (Jeffries \& Rizzolo, 2006), Feingold's satisfaction survey items of simulated clinical assessment (Feingold, Calaluce, \& Kallen, 2004), Baptista' Student satisfaction assessment scale with simulated clinical experiences (Baptista, Martins, Pereira, \& Mazzo, 2014), Tracy's satisfaction with simulation experience scale (Levett-Jones et al., 2011). One domesticliterature only searched is the simulation design scale (the SDS student version) (Yuan \& Bev- 
erly, 2014). Items of the scale were established based on all-round literature review on learning satisfaction with fidelity simulation.

\subsubsection{Semi-Structured Interview}

Descriptive qualitative research was used to analyze the nursing students' views on the learning satisfaction of high-fidelity simulation. A memorandum to the semi-structured personal in-depth interview with 8 nursing students from Yangtze University was enclosed. 8 nursing students with age of $20-23$ years $(22.4 \pm$ 1.07) were from the third-grade undergraduate. There were 6 females and 2 males, all with greater than or equal to two high-fidelity simulation exercises. Interview tools contained semi-structured interview outline. Semi-structured interview questions were as follows. 1) What do you think of high-fidelity simulation? 2) How do you feel during high-fidelity simulation exercise? 3) Which factors affect the learning satisfaction of high-fidelity simulation? All research members as interviewers except the postgraduate student are involved in the semi-structured interview. The quiet and tidy environment was selected to make the interview, usually in the small meeting room. Each interview took about 45 to 90 minutes. Recording and notebook were used to collect the data. All the interviews were sound recorded. The interviews data were managed by Nvivo 11.0 software and the topics were extracted by content analysis method. Add the results to item pools of the scale.

\subsection{Delphi Method}

\subsubsection{Expert Panel}

The inclusion criteria of the invited experts were that: 1) the experts had been engaged in nursing education for more than 10 years and high-fidelity simulation teaching for more than 3 years in hospitals or universities; 2) the experts had middle or high titles; 3 ) each expert should have master or doctor degree; 4) they all agreed to join in this study.

\subsubsection{Data Collection}

\section{1) Round 1}

With the literature review and semi-structured interview, the initial learning satisfaction scale items for nursing students with high-fidelity simulation were determined. Then a specialist consultation questionnaire (round 1) was framed, which included the degree of importance, judgment basis and the degree of familiarity. A 5-point Likert format was used to obtain extent of importance degree, with ranges from $5=$ strongly important to $1=$ strongly unimportant. The judgment basis included 4 formats, with $0.4=$ practical experience, $0.3=$ theoretical analysis, $0.2=$ reference data at home and abroad, $0.1=$ subjective choice. Opinions on retention, deletion or modification were framed with each item (Zhang et al., 2018). The specialist consultation questionnaires with basic status questionnaires were sent by E-mail, and feedback opinions were collected within 2 weeks. 
2) Round 2

On the basis of the results of Delphi's specialist consultation (round 1), the expert consultation (round 2) was carried out. The interval time between round 1 and round 2 was 1 month. The results of experts' opinions (round 2) were consistent.

\subsection{Statistical Analysis}

Objective criterions are as follows (Zeng, 1994). Items would be deleted with the means of importance score $\leq 1$ (round 1) or $\leq 2.5$ (round 2). If the coefficient of variation is $\leq 25 \%$, it is suggested that the degree of coordination of the item is high. If the variation coefficient ranges from $25 \%$ to $30 \%$, the degree of coordination is still acceptable. Items would be deleted with the variation coefficient $>$ $30 \%$. Data were analyzed by using SPSS 17.0 for Windows. Specialist positivity coefficient is expressed by the recovery rate of specialist consultation questionnaires; the concentrative degree is expressed by significance means and full mark ratio; the experts' authority coefficient $(\mathrm{Cr})$ is the degree of authority of experts on the evaluated indicators, which is defined as $\mathrm{Cr}=(\mathrm{Ca}+\mathrm{Cs}) / 2$; the agreement among responders is measured using Kendall's coefficient of concordance (W). Cronbach's Alpha was used for the verification of the internal consistency reliability of questionnaire. The test indicates the statistical significance $(\mathrm{P})$ of the correlation coefficient. $P<0.05$ was considered statistically significant.

\section{Results}

According to the result of literature review and structural interview, the initial set of the learning satisfaction scale for nursing students with high-fidelity simulation was established (Table 1).

\subsection{Expert Panel}

The expert panel comprised 18 experts with length of service 13 - 33 years (22.4 \pm 6.7). The experts worked in different comprehensive tertiary hospitals or universities in five provinces and cities of China (Table 2).

\subsection{Specialist Positivity Coefficient}

18 questionnaires of round 1 were sent out and 18 valid ones were retrieved, of which 17 experts gave opinions. The effective recovery rate was $100 \%$ and the opinion rate was $94.4 \% .18$ questionnaires of round 2 were sent out and 16 valid ones were retrieved, of which 6 experts gave opinions. The effective recovery rate was $88.9 \%$ and the opinion rate was $37.5 \%$. The recovery rate was more than $70 \%$, which indicated experts' high initiative.

\subsection{Specialist Authority Degree}

Specialist authority coefficients $(\mathrm{Cr}>0.70)$ mean a high expert authority degree of two Delphi rounds (Table 3). 
Table 1. The learning satisfaction scale for nursing students with high-fidelity simulation (first draft).

\begin{tabular}{ll}
\hline First grade indexes & Second grade indexes \\
\hline Simulation fidelity & Appearance fidelity of high-fidelity simulator \\
& Tactility of high-fidelity simulator \\
& Simulation effect of high-fidelity simulator \\
& Configuration quality \\
& Reliability of scenario simulation \\
& Authenticity of scenario simulation \\
& Students' participation of the establishment of experimental training plan \\
& Team cooperation \\
& Teacher-student interaction \\
& Teachers' lead-in reflection \\
& Teachers' analysis and summary \\
& Teachers' guidance and support \\
& Suitability of clinical scene \\
Suitability of practice content & Suitability of practice time \\
Learning effect & Difficult degree of practice \\
Combination of practice and theory & Learning perceived benefits \\
& Improvement of learning initiative \\
Learning content & Deeprongthening the memory of theoretical knowledge \\
&
\end{tabular}

Table 2. Characteristics of the expert panel $(n=18)$.

\begin{tabular}{llll}
\hline Characteristic & $\mathrm{n}$ & Characteristic & $\mathrm{n}$ \\
\hline Province & & Education level & \\
$\quad$ Shanghai & 4 & Master degree & 14 \\
Beijing & 2 & Doctor degree & 4 \\
Hubei & 8 & Title & \\
Sichuan & 3 & Middle professional title & 4 \\
Heilongjiang & 1 & High professional title & 14 \\
Gender & & Work place & \\
Male & 1 & In hospitals & 2 \\
Female & 17 & In universities & 16 \\
Ages & & & \\
30 - 39 years & 5 & & \\
40 - 49 years & 9 & & \\
$\geq 50$ years & 4 & & \\
\hline
\end{tabular}


Table 3. Specialist authority coefficient.

\begin{tabular}{cccc}
\hline Two Delphi rounds & Ca & Cs & Cr \\
\hline Round 1 & 0.84 & 0.89 & 0.87 \\
Round 2 & 0.85 & 0.91 & 0.88 \\
\hline
\end{tabular}

\subsection{Specialist Coordination Degree}

The coefficients of variation are all $<30 \%$, and the results of $X^{2}$-test are statistically significant. The degree of coordination is acceptable (Table 4).

\subsection{Reliability}

Cronbach's Alpha was used for the verification of the reliability of questionnaire. Cronbach's a was 0.72 in round 1 and Cronbach's $\alpha$ was 0.77 in round 2 . Cronbach's $\alpha$ of two tests was more than 0.7 , demonstrating the scale a reliable instrument.

\subsection{The Results of Twice Specialist Consultation}

After twice specialist consultation, there were 24 indexes remained in the final evaluation indicator system, including 4 first grade indexes and 20 second grade indexes. The results of first-round specialist consultation questionnaires were discussed and analyzed by the research team. Items were deleted with the means of importance score $\leq 1$ or the variation coefficient $>30 \%$. The modification of items was as follows: 1) the item "configuration quality" was deleted; 2) the item "reliability of scenario simulation" and the item "suitability of practice content" were deleted by reason of repeated contents; 3) "Simulation effect of high-fidelity simulator" was revised as "rationality of configuration settings (e.g. monitor)" by reason of the simulator not easily understood; 4) "teacher-student interaction" was deleted by reason of repeated contents of "teachers' lead-in reflection", "teachers' analysis and summary", "teachers' guidance and support"; 5) "difficult degree of practice" was replaced as "smoothness of practice process"; 6) "improvement of comprehensive clinical nursing ability" was revised as "improvement of clinical thinking ability" by reason of extensive contents; 7) "learning perceived benefits" was revised as "improvement of learning participation"; 8) first grade indexes "learning method", "learning content", "learning effect" were suggested to be modification of "teaching method", "teaching content", "teaching effect" by reason of only teaching contents of second grade indexes. Based on the results as above, second-round specialist consultation questionnaires were developed. The results of second-round specialist consultation questionnaires were discussed and analyzed by the research team again. Items were deleted with the means of importance score $\leq 2.5$. The modification of items was as follows: 1) to be more concretely, "smoothness of practice process" was revised as "smoothness of organizational procedure"; 2) "suitability of practice content" was revised as "suitability of clinical scene"; 3) "improvement of learning partic- 
ipation" was revised as "improvement of learning initiative". There was a consistent conclusion on the items after twice specialist consultation. Finally, an index system of 4 first grade indexes (simulation fidelity, teaching method, teaching content, teaching effect) and 20 second grade indexes was established (Table $5)$.

\section{Discussion}

\subsection{Reliability Analysis}

Literature review and semi-structured interview were conducted to establish the items of first draft. The expert panel comprised 18 experts with different province, gender, age, profession, education and length of service 13 - 33 years (22.4 \pm 6.7). There were qualifications and complementary advantages of the experts.

Table 4. The coordination coefficient of the specialists' opinion.

\begin{tabular}{ccccc}
\hline Two Delphi rounds & Coefficients of variation (\%) & Coordination coefficient & $X^{2}$ & $P$ \\
\hline Round 1 & $0-28.383$ & 0.809 & 362.675 & $0.000^{*}$ \\
Round 2 & $0-25.081$ & 0.848 & 300.188 & $0.000^{*}$ \\
\hline
\end{tabular}

${ }^{*} P<0.05$.

Table 5. The learning satisfaction scale for nursing students with high-fidelity simulation.

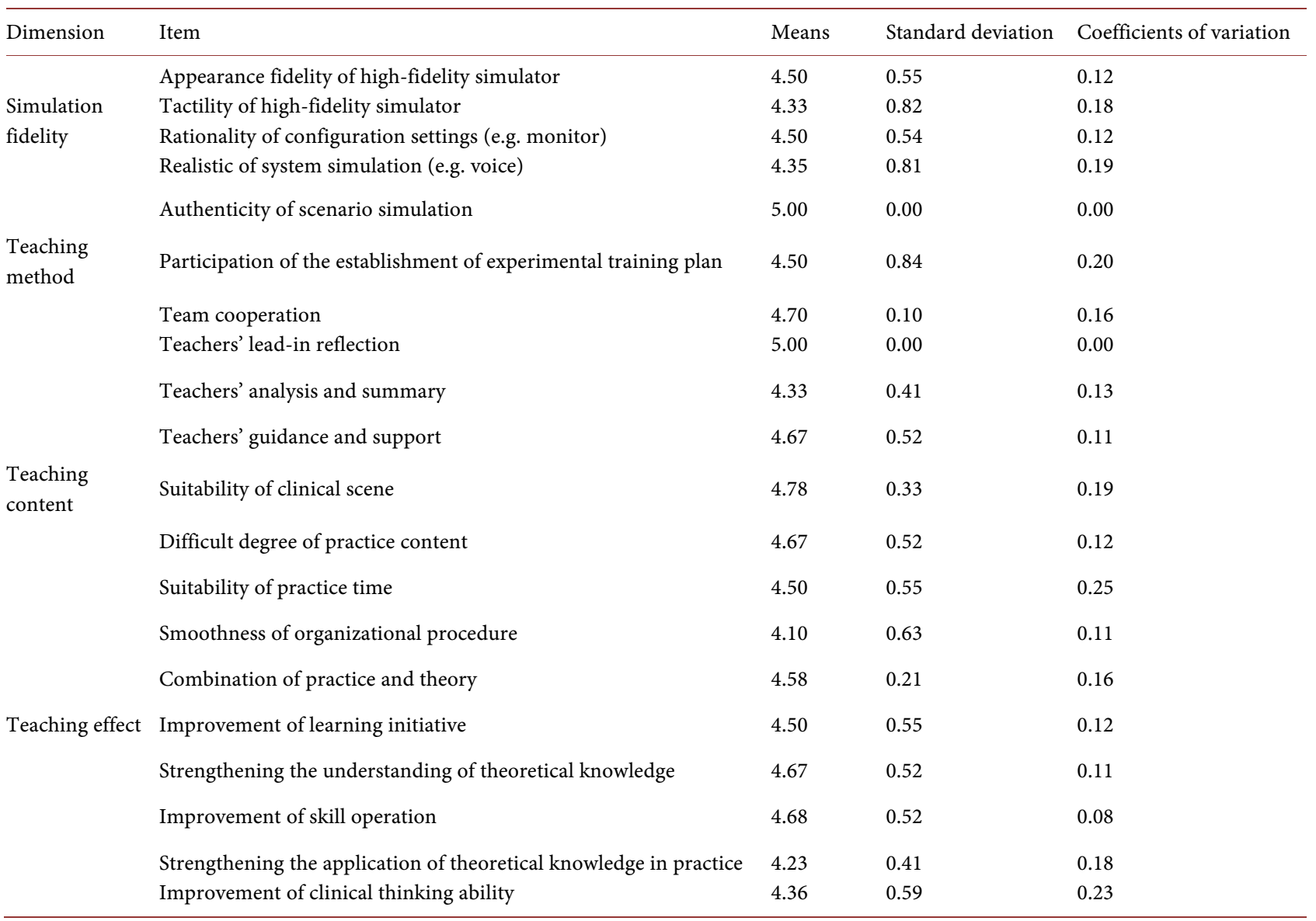


Active coefficient of the experts was comparatively high. The recovery rate of round 1 was $100 \%$ and the opinion rate was $94.4 \%$. The recovery rate of round 2 was $88.9 \%$ and the opinion rate was $37.5 \%$. Specialist authority coefficients $(\mathrm{Cr}>$ 0.70) (Zhang et al., 2018), means a high expert authority degree with round 1 $(\mathrm{Cr}=0.87)$ and round $2(\mathrm{Cr}=0.88)$. The coefficients of variation were all $<30 \%$ and coordination coefficients were all $>0.8$. The degree of coordination was acceptable with the results of $X^{2}$-test being statistically significant $(P<0.05)$. Cronbach's $\alpha$ was 0.72 in round 1 and Cronbach's $\alpha$ was 0.77 in round 2. Reliability was high in all items with Cronbach's $\alpha$ values $>0.70$.

\subsection{Significance of the Scale Construction}

The results of students' learning satisfaction can explain learning motivation and participation to great degree. Meanwhile, the results of learning satisfaction as the reference index for optimizing teaching resources can promote self-adjustment and continuous quality improvement. Thus, student learning satisfaction is an important indicator to measure the quality of teaching (Zhuge, $\mathrm{Wu}, \& \mathrm{Li}, 2013$ ). Bremner (Bremner, Aduddell, Bennett, \& VanGeest, 2006) suggested that there was a great correlation between students' learning satisfaction and behavioral expression. Prion (Zhuge, $\mathrm{Wu}, \& \mathrm{Li}, 2013$ ) also suggested that the extent of students' learning satisfaction had a positive correlation with degree of learning participation. At present, the nursing courses with high-fidelity simulation are as follows: basic nursing science, internal nursing science, surgical nursing science, pediatric nursing science, Obstetrics and Gynecology Nursing Science, health assessment, etc (Guo, Liu, \& Lei, 2011; Guo, Chen, \& Hong, 2013). However, there is no generally accepted evaluation method to comprehensively evaluate learning satisfaction with high-fidelity simulation in China (Zhan, Guo, \& Xu, 2014). Therefore, development of the scale has an important significance not only to fill up the domestic blank, but also to accelerate nationwide and international communication in nursing education. An index system of 4 first grade indexes (simulation fidelity, teaching method, teaching content, teaching effect) and 20 second grade indexes was established.

\subsection{Limitations}

Firstly, the Delphi method was mainly conducted to establish the items of the scale, which was depend on the subjective judgment of experts and lack of objective criteria. Thus, the Delphi method may affect the accuracy of the results. Secondly, It is limited that semi-structured personal in-depth interview only with nursing undergraduate students was used to supplement the scale items, without the graduate students investigated.

\subsection{Further Research Suggestions}

A survey with the big sample is needed to carry on for assessing the reliability and validity of the scale in the future research to generate a more objective and 
exact measurement scale for nursing students' learning satisfaction with highfidelity simulation. Meanwhile, it is suggested to do research on nursing students with different educational backgrounds for a more overall evaluation.

\section{Funding and Support}

This study was supported by teaching research program of Yangtze University (JY2017055), and Medical and Health Science and Technology Project of Jingzhou Science and Technology Bureau (2017-90), and teaching research program of Yangtze University (JY2016042).

\section{Ethical Approval}

This study was approved by Yangtze University ethics committee. Informed consent was given by all participants.

\section{Conflicts of Interest}

The authors declare no conflicts of interest regarding the publication of this paper.

\section{References}

Baptista, R. C., Martins, J. C., Pereira, M. F., \& Mazzo, A. (2014). Students' Satisfaction with Simulated Clinical Experiences: Validation of an Assessment Scale. Revista Latino-Americana de Enfermagem, 22, 709-715.

https://doi.org/10.1590/0104-1169.3295.2471

Bremner, M. N., Aduddell, K., Bennett, D. N., \& VanGeest, J. B. (2006). The Use of Human Patient Simulators: Best Practices with Novice Nursing Students. Nurse Education, 31, 170-174. https://doi.org/10.1097/00006223-200607000-00011

Feingold, C. E., Calaluce, M., \& Kallen, M. A. (2004). Computerized Patient Model and Simulated Clinical Experiences: Evaluation with Baccalaureate Nursing Students. Journal of Nursing Education, 43, 156-163. https://doi.org/10.3928/01484834-20040401-03

Gaba, D. M., \& DeAnda, A. (1988). A Comprehensive Anesthesia Simulation Environment: Re-Creating the Operating Room for Research and Training. Anesthesiology, 69, 387-394. https://doi.org/10.1097/00000542-198809000-00017

Guo, H. X., Chen, H., \& Hong, C. (2013). Applied Status of Simulation Teaching in Nursing Education in China. Nursing Research, 27, 2939-2941.

Guo, H., Liu, L., \& Lei, L. (2011). Application of Experimental Simulation Training in Nursing Education. Journal of Nurses Training, 26, 1263-1265.

Jeffries, P. R., \& Rizzolo, M. A. (2006). Designing and Implementing Models for the Innovative Use of Simulation to Teach Nursing Care of Ill Adults and Children: A National, Multi-Site, Multi-Method Study. New York: National League of Nursing.

Leigh, G. T. (2008). High-Fidelity Patient Simulation and Nursing Students' Self-Efficacy: A Review of the Literature. International Journal of Nursing Education Scholarship, 5, 1-37. https://doi.org/10.2202/1548-923X.1613

Levett-Jones, T., McCoy, M., Lapkin, S., Noble, D., Hoffman, K., Dempsey, J., \& Roche, J. (2011). The Development and Psychometric Testing of the Satisfaction with Simulation Experience Scale. Nurse Education Today, 31, 705-710. 
https://doi.org/10.1016/j.nedt.2011.01.004

Parr, M. B., \& Sweeney, N. M. (2006). Use of Human Patient Simulation in an Undergraduate Critical Care Course. Critical Care Nursing Quarterly, 29, 188-198. https://doi.org/10.1097/00002727-200607000-00003

Sun, J. P., Niu, G. F., Yang, Z. L., Li, H. M., Gao, H. L., \& Zhang, G. H. (2011). Application of High-Fidelity Human Patient Simulation in Nursing Education: A Review. Chinese Journal of Nursing Education, 8, 18-20.

Wu, T., Liu, L., \& Wu, B. (2014). Influence of Nursing Simulation Training Basis on Nursing Students' Creativity. Journal of Nursing Administration, 14, 518-519.

Xiao, Q., \& Wu, Y. (2009). Application of Simulation Teaching in Nursing Education. Chinese Journal of Nursing Education, 6, 216-218.

Yuan, H. B., \& Beverly, A. W. (2014). The Design Features of Nursing Simulation and the Correlations with the Students' Confidence and Satisfaction. Nursing Research, 28, 2561-2565.

Zeng, G. (1994). Modern Epidemiological Methods and Applications. Beijing: Beijing Medical University Press and Peking Union Medical College Press.

Zhan, L. Y., Guo, Q., \& Xu, H. (2014). Teaching Effect and Evaluation Tools of HighFidelity Simulation for Nursing Students: A Review Literature. Chinese Journal of Nursing Education, 11, 898-902.

Zhang, Y., Ji, C. H., Li, Q. S., Lu, H. T., Wu, D. J., Ye, B. D., \& Cao, Y. (2018). Statistical Analysis Method of Delphi Technique Used in Clinical Practice Guideline of Traditional Chinese Medicine. China Journal of Traditional Chinese Medicine and Pharmacy, 33, 249-251

Zhuge, F. M., Wu, Z. L., \& Li, S. N. (2013). Research on Technological University Students' Learning Satisfaction: A Case Study at Shandong University of Science and Technology. Journal of Shandong University of Science and Technology (Social Sciences), 15, 96-102.

Ziv, A., Small, S. D., \& Wo, P. R. (2000). Patient Safety and Simulation-Based Medical Education. Medical Teacher, 22, 489-495. https://doi.org/10.1080/01421590050110777 